\title{
Research of Dynamic Negotiation Model Based on Mobile Agent
}

\author{
Fang Guo \\ School of Management \\ Dalian Polytechnic University \\ Dalian, China \\ guofang@dlpu.edu.cn
}

\author{
Jie Xiao \\ School of Management \\ Dalian Polytechnic University \\ Dalian, China \\ xiaojie_dlpu@163.com
}

\begin{abstract}
On the basis of the present negotiation theories and models, a dynamic negotiation model based on mobile agent is put forward. This model supports a continuous and dynamic negotiation environment, making all the buyers and sellers participate in or exit from negotiation freely, and forming a competitive system. It also puts forward a dynamic concession strategy based on opponents attitude learning is proposed. By learning the track of the proposals, agents can understand each other's preferences, attitude and urgency. Then, it helps both parties to make decision under a dynamic environment and achieve maximum utility. Finally, a test system of the model is built to verify whether the system is correct and has operability and scalability or not.
\end{abstract}

Keywords- E-commerc; Dynamic Negotiation; Mobile Agent;Multithreading

\section{INTRODUCTION}

E-commerce negotiation is a process in which two or more parties resolve the conflict with the computer and network technology, and finally reach an agreement on the terms of a transaction [1]. When facing the development of E-commerce business and an increase in the number of network users, defects of E-commerce negotiation emerge, manifesting themselves as low degree of automation, inefficiency, weakness in timeliness, design and application ability. In the existing E-commerce negotiation models, many-to-many negotiation model generally uses a centralized method which is regarded as a simply superposition of multiple concurred one-to-one negotiation models [2]-[6]. Buyer agents must fully receive all of the proposals from seller agents, and then make further decision. In this way, buyers and sellers are difficult to get the best results of the consultation and negotiation efficiency.

This article is aimed to build a new mobile agent-based dynamic negotiation model based on the existing negotiation theories and models. In the new model, all the buyers and sellers' agents are composed of a coordinator and multiple negotiation threads. Coordinator updates the optimal solution of the current consultation, and informs each negotiation thread promptly. Mobile agent-based dynamic negotiation model not only solves the problem of waiting between each agent, but also makes all the sellers who meet the initial condition participate in the negotiation. In the negotiation process, we take a concession strategy based on the learning of opponents' attitude. Agent judges the opponents' attitude combined with the utility value of the opponents' proposals and the proposal's concessions magnitude. And then it formed a kind of competitive system between all of the parties which can help them to make decision under a dynamic environment. Both buyers and sellers will get the best result of the negotiation.

\section{NEGOTIATION MODEL}

\section{A. Basic Hypothesis}

Negotiation model must be established under the premise of a series of assumptions given the real situation[7]. Generally, agents who participate in the autonegotiation process have the following characteristics[8][10]:

1) They are limited rational, intelligent and selfcentered;

2) They represent the seller or the buyer's preferences and accomplish the corresponding task;

3 ) One agent can't acquire all the information from others;

4) Agents can pursue their own interest in a limited time.

This model is based on the several basic assumptions, as follows:

H1: Agents are selfish, pursuing self-interest maximization;

H2: Agents have limited rationality. The strategies adopted by the agents represent their own optimal strategy;

H3: Information asymmetry. Agents can not grasp the other's preferences completely;

H4: Agents negotiate with others only in a limited time;

H5: Negotiating parties are sincere without cheating;

H6: The failure of negotiation is the worst result for all parties;

H7: The transaction is carried out in a free competitive market.

B. Model Framework

Mobile agent-based dynamic negotiation model framework is defined as a nine-tuple:

Model $=<\mathrm{Ag}, \mathrm{Q}, \mathrm{X}, \mathrm{W}, \mathrm{V}, \mathrm{U}, \mathrm{T}, \mathrm{R}, \mathrm{O}>\quad$ (1)

$\mathrm{Ag}$ : A set involved all of the agents which participate in the negotiation. Agb means the buyer agent, Ags means the seller agent. Due to multiple buyer and seller's agents participating in the negotiation at the same time, it is 
defined that Agbi $\in($ Agb1, Agb2, $\cdots \cdots$, Agbn $)$, Agsi $\in$ (Ags1, Ags2, $\cdots$, Agsn).

Q: A set involved all of the negotiation items. $Q=\{Q 1$, $\mathrm{Q} 2, \cdots \mathrm{Qj}\}, \mathrm{Qj}$ means the $\mathrm{j}$-th consultation item, $\mathrm{j}$ means items number $(\mathrm{J} \geqslant 2)$.

$\mathrm{X}$ : A set involved all of the negotiation proposals. Xij means a proposal of $\mathrm{Qj}$ which is raised by agent.

W: A set involved all of the negotiation items' weight. $\mathrm{W}=\{\mathrm{Wi} 1, \mathrm{Wi} 2, \cdots, \mathrm{Wij}\}, 1 \leqslant \mathrm{j} \leqslant \mathrm{J}, \Sigma \mathrm{Wij}=1$.

$\mathrm{V}$ : A set involved all of the evaluation function. $\mathrm{Vij}(\mathrm{Xij})$ means evaluation of the proposal Xij $(j \in Q, i \in A g)$.

$\mathrm{U}$ : A set involved all of the utility function, $\mathrm{Ui}=\Sigma \mathrm{Wij}$ Vij(Xij).

T: A period of negotiation. Negotiate will be suspended if agents can not reach an agreement within limited time.

$\mathrm{R}$ : A set involved all of the negotiation operation. $\mathrm{R}=\{$ call, request, proposal, counterproposal, reject, accept $\}$.

$\mathrm{O}$ : The optimal value of the current negotiation. $\mathrm{O}$ will delegate the final result until agreement is successfully made.

\section{Decision function}

In the negotiation process, agent will evaluate each proposal as the basis of an overall assessment. Because of the opposite interest of buyer and seller, they have opposite evaluation on a same project. In this paper, the evaluation function is defined as simple linear monotonically decreasing or monotonically increasing function:

$$
\mathrm{V}_{\mathrm{i}}{ }^{\mathrm{j}}\left(\mathrm{X}_{\mathrm{i}}{ }^{\mathrm{j}}\right)=\frac{\max _{\mathrm{i}}{ }^{\mathrm{j}}-\mathrm{X}_{\mathrm{i}}{ }^{\mathrm{j}}}{\max _{\mathrm{i}}{ }^{\mathrm{j}}-\min _{\mathrm{i}}{ }^{\mathrm{j}}} \quad \text { (Monotonically decreasing }
$$

function)

$$
\mathrm{V}_{\mathrm{i}}^{\mathrm{j}}\left(\mathrm{X}_{\mathrm{i}}^{\mathrm{j}}\right)=\frac{\mathrm{X}_{\mathrm{i}}^{\mathrm{j}}-\min _{\mathrm{i}}^{\mathrm{j}}}{\max _{\mathrm{i}}{ }^{\mathrm{j}}-\min _{\mathrm{i}}{ }^{\mathrm{j}}} \text { (Monotonically increasing }
$$

function)

According to their own interests on different projects, buyer and seller agent select different evaluation function for each project. For the same proposal, two parties will select the opposite evaluation function.

In addition, different people have different preferences for different items in a negotiation process, so they must give different weights to different projects. Items with higher weight will generate bigger effect on the results, so that evaluation of the various projects is not the average effect for the last utility. The utility function is defined as follows:

$$
\mathrm{U}_{\mathrm{i}}=\sum_{\mathrm{j}=1}^{\mathrm{J}} \mathrm{W}_{\mathrm{i}}^{\mathrm{j}} \mathrm{V}_{\mathrm{i}}^{\mathrm{j}}\left(\mathrm{X}_{\mathrm{i}}^{\mathrm{j}}\right), 1 \leq \mathrm{j} \leq \mathrm{J}, \mathrm{i} \in\left(\mathrm{Ag}_{\mathrm{b}}, \mathrm{Ag}_{\mathrm{si}}\right)
$$

Utility function can distinguish different projects through their different weight values, and then make the overall evaluation according to user's preference. Having compared with the expected utility value of buyer and the utility value given by sellers, buyer agent would decide whether to accept the proposal or not and whether to continue the negotiation.

\section{Concession strategy}

In the negotiation process, all of the proposals given by agents are generated in the process of repeated consultations dynamically, except the first proposal which is set according to its initial value. Therefore, there must be a specific concession strategy ${ }^{[11]}$. A dynamic concession strategy based on an opponent's attitude learning is adopted in this paper. Intelligent agent evaluates the received proposal, and then learns each other's preferences, attitude and urgency through the study of the average utility value and other proposed track. Afterwards, it offers counter-proposal on the account of self-interest and other's proposals.

During the consultations, agent will make concessions after evaluating received proposals. If one proposal receives a higher evaluation value, it illustrates that the proposal is closed to the expected value of the target agent. In other words, there is larger space for the agent to make concessions. On the contrary, if one proposal receives a lower evaluation values, the agent can only make a smaller magnitude concession, even make no concession. And then agent rejects the proposal directly, and exit from consultation.

Next, in order to judge each other agent's preferences, attitudes and urgency, agents calculate the utility value of all of the proposals respectively and the average utility value. If the utility value of one proposal is higher than the average utility value, and the agent make more substantial concessions, it indicates that the urgency of the agent is higher, and it have a strong desire to reach agreement. Therefore, the agent makes compromise more easily. If the utility value of one proposal is lower than the average utility value and the agent make less substantial concessions, it indicates that the urgency of the agent is lower. Therefore, the agent is not easy to compromise.

Finally, agents give their own counter-proposals after taking self-interest and counterpart' $s$ attitude into account.

\section{NEGOTIATION ALGORITHM PROCESS}

In order to solve the problem of low negotiation efficiency, this article applies the concept of multi-thread to the negotiation model. For example, there is one buyer to many sellers. The buyer agent is composed of a coordinator and multiple negotiation threads. Coordinator creates a corresponding number of negotiation threads according to the number of the sellers. These negotiation threads and sellers conduct one-on-one consultations. The coordinator records and notices optimal value of each thread consultation promptly, and conducts centralized control on these threads. Negotiation algorithm processes is described as shown in Figure 1.

step 1: All of the sellers who are in a competitive market create their agents, and then wait for a buyer agent to negotiate;

step 2: According to their own situation, buyer expects their utility function value, and makes a request to seller agent after doing the initial definition. The buyer agent is composed of a coordinator and multiple negotiation threads. Coordinator creates a corresponding number of negotiation threads according to the number of the sellers. These negotiation threads and sellers conduct one-on-one consultations; 
step 3: If the buyer agent waits for a response time beyond the limit, or the seller agent refuses the request of the buyer agent, negotiation fails. Else continues with step (4);

step 4: Sellers issue the first proposal to the buyer agent respectively after accepting the request of the buyer agent;

step 5: After receiving the proposal from seller agent, buyer agent evaluates its utility, and then makes decision. Each thread of the buyer agent runs independently, and reports its status to the coordinator after each round of negotiations. The coordinator selects the most optimal solution for further negotiation;

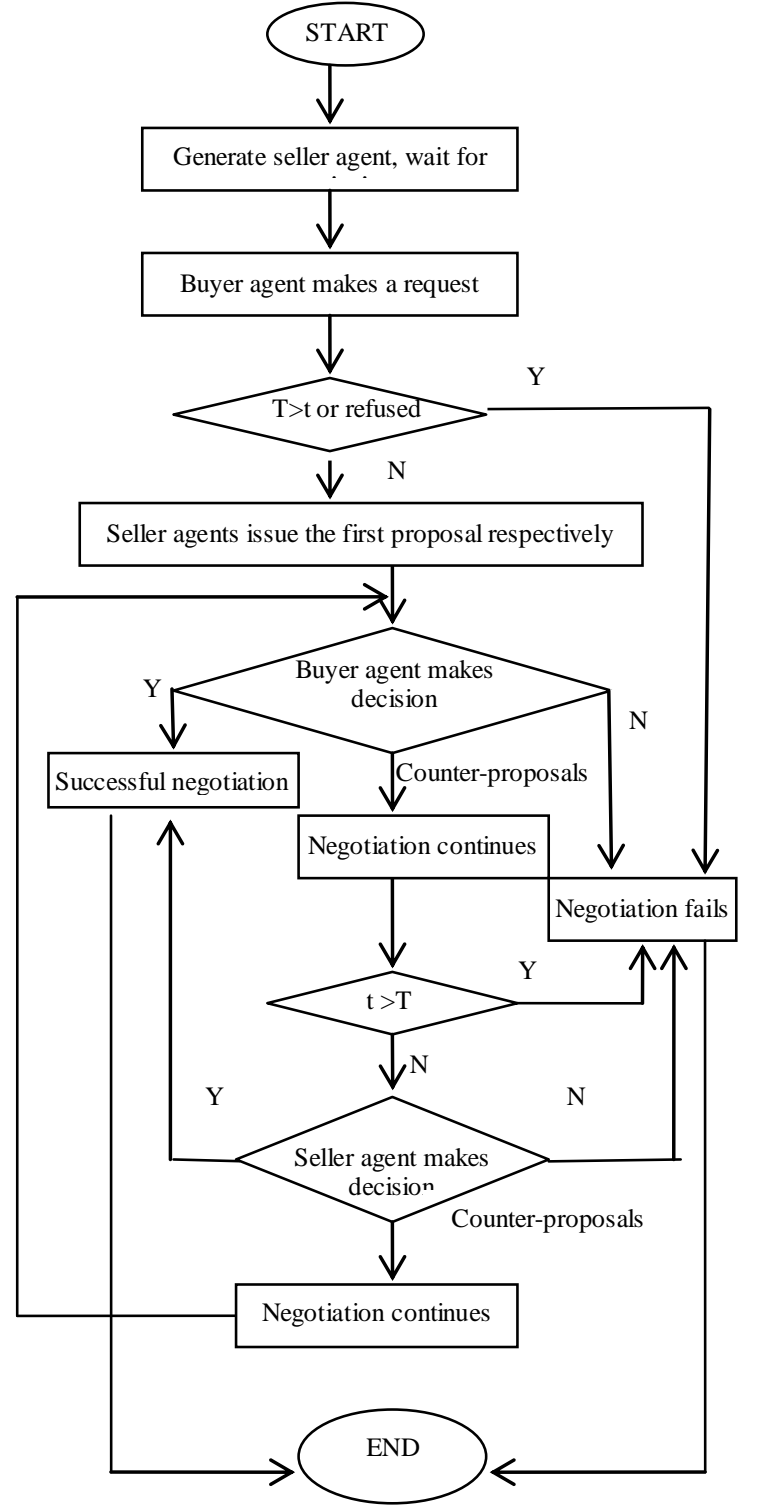

Figure 1. Negotiation algorithm process

Step 6: After receiving a counter-proposal from the buyer agent, seller agent also evaluates its utility, and then makes decision;

Step 7: Buyer and seller agent will cycle through the step 5 and 6 until an agreement is reached. Then buyer agent informs the coordinator of negotiation results. The coordinator notices other threads refused their seller's agent to end negotiation. If all the proposals of buyer agent's threads are refused, negotiation fails;

Step 8: The results of the negotiation are sent back to the agents respectively.

In the step 7, if the buyer agent makes successful negotiation with more sellers at the same time, the coordinator will evaluate utility value of every result which is returned by the threads, and select a seller with the highest value.

In the process of the negotiation, new seller agent may join the current negotiation at any time. The buyer agent coordinator will create a new negotiation threads, and negotiate with the seller with optimal proposal it has got. A thread will end as well when the seller agent wants to exit from the negotiation.

\section{EXPERIMENTAL SIMULATION AND RESULTS ANALYSIS}

This article designs and implements a simple ecommerce negotiation simulation system by means of mobile agent technology in LAN. The system uses B/S structure, and auxiliary Eclipse as a programming tool, Tomcat as a Web server, MongoDB as a data storage tool to develop the system.

Conduct a simulated negotiation supposing there is one buyer and many sellers, and initiate it as a buyer. The buyer who lived in Dalian wants to buy a book online. There are seven sellers who can provide this book, as shown in Table 1. Assuming that all sellers' books have the same quality, but the price, delivery time and postage are different.

TABLE 1. SELLERS' INITIAL INFORMATION

\begin{tabular}{|l|l|l|l|l|}
\hline $\begin{array}{c}\text { Seller } \\
\text { Name }\end{array}$ & $\begin{array}{c}\text { Price } \\
\text { (yuan) }\end{array}$ & $\begin{array}{c}\text { Warehouse } \\
\text { Location }\end{array}$ & $\begin{array}{c}\text { Delivery } \\
\text { Time } \\
\text { (day) }\end{array}$ & $\begin{array}{c}\text { Postal } \\
\text { Charges } \\
\text { (yuan) }\end{array}$ \\
\hline Seller1 & 22.80 & Hangzhou & 4 & 10 \\
Seller2 & 19.60 & Harbin & 6 & 15 \\
Seller3 & 20.50 & Shijiazhuang & 5 & 10 \\
Seller4 & 18.90 & Beijing & 3 & 15 \\
Seller5 & 20.20 & Dalian & 7 & 15 \\
Seller6 & 16.90 & Beijing & 5 & 10 \\
Seller7 & 17.80 & Xiamen & 7 & 15 \\
\hline
\end{tabular}

The data listed in Table 1 are the initial information of the seller agent. However, the product price, delivery time and postal charges of the seller agent are not a fixed value; they have an acceptable negotiation range as shown in Table 2. Seller agents make concessions in this range. If the current negotiation optimal value is out of the range, they will exit from the negotiation and end the corresponding thread.

In the transaction process, buyer only cares the total cost of the product, so the weight is given to the total cost. The total cost is composed of the product price and the postal charges. Assuming that the weight of the total cost is 0.7 , and the weight of delivery time is 0.3 . After the auto-negotiation between the agents, the final results of the negotiation are listed as shown in Table 3. Evaluate 
the results of the negotiation with the evaluation function, and finally get the utility value of the negotiation results, as shown in Table 4. Buyer makes decision according to the utility value, and reaches an agreement with Seller 5.

TABLE 2. THE RANGE OF SELLER NEGOTIATION

\begin{tabular}{|l|c|l|l|}
\hline Seller Name & Price (yuan) & $\begin{array}{c}\text { Delivery Time } \\
\text { (day) }\end{array}$ & $\begin{array}{c}\text { Postal Charges } \\
\text { (yuan) }\end{array}$ \\
\hline Seller1 & {$[16.80,22.80]$} & {$[1,4]$} & {$[5,10]$} \\
Seller2 & {$[16.60,19.60]$} & {$[1,6]$} & {$[3,15]$} \\
Seller3 & {$[17.00,20.50]$} & {$[1,5]$} & {$[3,10]$} \\
Seller4 & {$[16.00,18.90]$} & {$[1,3]$} & {$[5,15]$} \\
Seller5 & {$[17.30,20.20]$} & {$[1,7]$} & {$[3,15]$} \\
Seller6 & {$[15.80,16.90]$} & {$[1,5]$} & {$[5,10]$} \\
Seller7 & {$[15.30,17.80]$} & {$[1,7]$} & {$[5,15]$} \\
\hline
\end{tabular}

TABLE 3. SELLER'S FINAL RESULTS OF THE NEGOTIATION

\begin{tabular}{|l|l|l|l|l|}
\hline $\begin{array}{c}\text { Seller } \\
\text { Name }\end{array}$ & \multicolumn{1}{|c|}{$\begin{array}{c}\text { Price } \\
\text { (yuan) }\end{array}$} & $\begin{array}{c}\text { Delivery } \\
\text { Place }\end{array}$ & $\begin{array}{c}\text { Delivery } \\
\text { Time } \\
\text { (day) }\end{array}$ & $\begin{array}{c}\text { Postal } \\
\text { Charges } \\
\text { (yuan) }\end{array}$ \\
\hline Seller1 & 17.20 & Dalian & 4 & 10 \\
Seller2 & 17.00 & Dalian & 2 & 5 \\
Seller3 & 17.50 & Dalian & 3 & 5 \\
Seller4 & 16.00 & Dalian & 3 & 8 \\
Seller5 & 18.80 & Dalian & 1 & 3 \\
Seller6 & 16.50 & Dalian & 5 & 5 \\
Seller7 & 15.30 & Dalian & 7 & 10 \\
\hline
\end{tabular}

TABLE 4. SELLER'S FINAL UTILITY INFORMATION OF THE NEGOTIATION

\begin{tabular}{|c|c|c|c|}
\hline & Total Cost(yuan) & $\begin{array}{c}\text { Delivery Time } \\
\text { (day) }\end{array}$ & \multirow{2}{*}{$\mathbf{U}_{\mathbf{i}}$} \\
\hline $\mathbf{A g}_{\mathbf{s i}}$ & 0.7 & 0.3 & \\
\hline Seller1 & 0.122 & 0.091 & 0.113 \\
\hline Seller2 & 0.151 & 0.181 & 0.160 \\
\hline Seller3 & 0.148 & 0.121 & 0.140 \\
\hline Seller4 & 0.139 & 0.121 & 0.134 \\
\hline Seller5 & 0.153 & 0.362 & 0.216 \\
\hline Seller6 & 0.155 & 0.072 & 0.130 \\
\hline Seller7 & 0.132 & 0.052 & 0.108 \\
\hline
\end{tabular}

Experimental result shows that the model reaches a high utility. All the sellers who meet the condition can participate in the negotiation, and make concessions based on their actual situation. Sellers can satisfy the buyer's demand, ensure their own interests at the same time, and finally achieve a win-win situation.

\section{CONCLUSION}

This article puts forward one kind of mobile agentbased dynamic negotiation model which is on the basis of the existing negotiation theories and models. This model supports a continuous and dynamic negotiation environment, allowing all the buyers and sellers to participate in or exit from negotiation freely, and forming a kind of competitive system. Then, it assists both parties to make decision under a dynamic environment and finally get the optimal results of the negotiation. However, negotiation efficiency of the model can not be effectively verified. Future research could concentrate on the way in which negotiation efficiency of the model can be raised.

\section{REFERENCES}

[1] HU Xiang-pei, CHENG Qiao, XU Zhi-chao. (2007). Review of ECommerce Negotiation Models. Systems Engineering and Electronics, 29 (10):1650-1654.

[2] SUN Tian-hao, ZHU Qing-sheng, LI Shuang-qing. (2009). Research on One-to-Many Negotiation Model. Journal of Electronics \& Information Technology, 31(5): 1031-1034.

[3] M.Delaney, A.Foroughi, W.Perkins. (2005). An empirical study of the efficacy of a computerized negotiation support system(NSS). Decision Support Systems, 20(3): 185-197.

[4] Iyad Rahwan, Ryszard Kowalczyk, Ha Hai Pham. (2002). Intelligent Agents for Automated One-to-Many e-Commerce Negotiation. Australian Computer Science Communications, 24(1):22-29.

[5] WU Li-qiao, YU Chun-yan, WANG Hong-shu. (2011). Study and Simulation of Multi-Agent Negotiation Competition Model. Computer Engineering, 37(10): 176-178.

[6] Dong-Her Shih, Shin-Yi Huang, David C.Yen. (2005). A new reverse auction agent system for $\mathrm{m}$-commerce using mobile agents. Computer Standards \& Interfaces, 27(2): 383-395.

[7] WANG Zhao-ming, LING Yong-hui. (2007). Research of Static Model in Electronic Commerce Trade Negotiation based on Agent. Chinese Journal of Management Science, 15(8):454-458.

[8] Braynov S, Sandholm T. (2008). Contracting with uncertain level of trust. Computational Intelligence, 18(4): 125-14.

[9] KANG Zhen-ke, DONG Dong, WANG Yan-xia. (2010). MultiAgent Multi-stage One-to-many Negotiation Model. Computer Engineering and Design, 31(18): 4072-4075.

[10] Malamati Louta, Ioanna Roussaki, Lambros Pechlivanos. (2008). An intelligent agent negotiation strategy in the electronic marketplace environment. European Journal of Operational Research, 187(8):1327-1345.

[11] XIANG Chuan-jie, JIA Yun-de. (2010). New E-Commerce Model Based on Multi-Agent Automated Negotiation. Journal of Beijing Institute of Technology, 12(4):432-435. 